\title{
Evaluation of the Infection-Related Ventilator-Associated Events Algorithm for Ventilator-Associated Pneumonia Surveillance in a Trauma Population
}

\author{
Annop Piriyapatsom MD, Hsin Lin PharmD, Massimiliano Pirrone MD, Gennaro De Pascale MD, \\ Javier Corona De Lapuerta MSc, Edward A Bittner MD, Ulrich H Schmidt MD, \\ Marc De Moya MD, and Lorenzo Berra MD
}

\begin{abstract}
BACKGROUND: The Centers for Disease Control and Prevention have recently introduced new ventilator-associated pneumonia (VAP) surveillance on the basis of the infection-related ventilator-associated complication (IVAC) definition. We aim to evaluate the accuracy of this new IVAC algorithm for detecting VAP according to the 2008 Centers for Disease Control and Prevention/National Healthcare Safety Network (NHSN) definition as the reference diagnosis (VAP-NHSN) in high-risk trauma patients. METHODS: This retrospective single-center study included all trauma subjects who were admitted to the ICU, required mechanical ventilation for $>48 \mathrm{~h}$, and received a blood transfusion. The new IVAC surveillance and the criteria for VAP-NHSN diagnosis were applied. The accuracy of the new IVAC surveillance for detecting VAP-NHSN was determined, and the clinical outcomes were compared between groups. RESULTS: The sensitivity, specificity, and positive and negative predictive values of IVAC for VAP-NSHN identification were $28.12 \%, 91.45,58.06 \%$, and $75.14 \%$, respectively. Subjects with IVAC, VAP-NHSN, or both had higher morbidity when compared with those without IVAC and VAP-NHSN. Subjects with IVAC only had lower morbidity compared with those with VAP-NHSN only or those with both IVAC and VAP-NHSN. There was no significant difference in clinical outcomes between subjects with VAP-NHSN only and those with both IVAC and VAP-NHSN. CONCLUSIONS: IVAC criteria had a low accuracy for identifying VAP-NHSN in subjects with high-risk trauma. Key words: accuracy; critical care; trauma; ventilator-associated events; ventilator-associated pneumonia. [Respir Care 2016;61(3):269-276. ( 2016 Daedalus Enterprises]
\end{abstract}

\section{Introduction}

Ventilator-associated pneumonia (VAP) is one of the most common hospital-acquired infections among mechan-

\footnotetext{
Dr Piriyapatsom is affiliated with the Department of Anesthesiology, Siriraj Hospital, Mahidol University, Bangkok, Thailand. Dr Lin is affiliated with the Department of Pharmacy; Drs Pirrone, De Pascale, Corona De Lapuerta, Bittner, and Berra are affiliated with the Department of Anesthesia, Critical Care, and Pain Medicine; and Dr De Moya is affiliated with the Division of Trauma, Emergency Surgery, and Surgical Critical Care, Department of Surgery, Massachusetts General Hospital, Harvard University, Boston, Massachusetts. Dr Schmidt is affiliated with the Department of Anesthesiology, University of California, San Diego, California.
}

The authors have disclosed no conflicts of interest. ically ventilated patients. ${ }^{1}$ Patients with VAP carry significantly higher morbidities, including longer duration of mechanical ventilator support as well as longer ICU and hospital stay ${ }^{1}$ and higher mortality ${ }^{2}$ than those without VAP.

According to the Centers for Disease Control and Prevention (CDC) and National Healthcare Safety Network (NHSN) surveillance definition of healthcare-associated infection published in $2008,{ }^{3}$ signs and symptoms such as

\footnotetext{
Correspondence: Lorenzo Berra MD, Department of Anesthesia, Critical Care, and Pain Medicine, Massachusetts General Hospital, Harvard University, 2 Fruit Street, Boston, MA 02114. E-mail: 1berra@mgh.harvard.edu.
}

DOI: $10.4187 /$ respcare. 04280 
fever, leukocytosis, or leukopenia; deterioration in oxygenation; changes in characteristics of respiratory secretions; and microbiological evidence of pulmonary infection are used in combination with changes in serial chest radiographs to make the diagnosis of VAP. These criteria

\section{See the Related Editorial on Page 390}

are widely accepted as a clinical standard for VAP diagnosis. However, they have been criticized as lacking objective definitions and having a high degree of intraobserver and inter-observer variability. ${ }^{4}$ Recently, the CDC has published a new algorithm for surveillance of ventilator-associated events. ${ }^{5}$ This algorithm mainly focuses on identifying mechanically ventilated patients who have worsening respiratory status resulting from various causes $^{6-11}$ on the basis of changes in support, namely PEEP and/or $\mathrm{F}_{\mathrm{IO}_{2}} \cdot{ }^{5}$ The term infection-related ventilator-associated complications (IVACs) is applied when a ventilator-associated event is associated with leukocytosis/leukopenia or hypothermia/hyperthermia plus administration of new antimicrobial agents. ${ }^{5}$ Furthermore, the terms possible and probable VAP are applied to IVAC patients if there is evidence of pulmonary infection defined as purulent respiratory secretions and/or positive culture of lower respiratory tract specimens. ${ }^{5}$ The main objectives of this newly developed algorithm are to increase the reliability, reproducibility, comparability, and efficiency of the surveillance and to improve patient safety in the ICU. ${ }^{12,13}$ Despite this, recent studies in mechanically ventilated subjects have shown that the IVAC definition has poor accuracy in identifying patients with VAP.6,8,10

Trauma patients are known to carry a higher incidence of VAP compared with the nontrauma population. ${ }^{1,14,15}$ Risk factors for VAP in these patients are well-described, including site and severity of trauma, ${ }^{16,17}$ duration of mechanical ventilator support, ${ }^{16}$ and transfusion of packed red blood cells. ${ }^{18-20}$ To the best of our knowledge, there are very limited data regarding ventilator-associated event surveillance in the high-risk trauma patient population. We hypothesize that, on the basis of the IVAC algorithm, some high-risk trauma patients with VAP would be not identified and, on the other hand, patients who are identified having IVAC actually do not have VAP. We therefore aimed to determine the accuracy of the IVAC surveillance for detecting VAP as identified with the VAP-NHSN criteria in subjects with high-risk trauma and to describe characteristics and clinical outcomes in subjects with and without IVAC.

\section{QUICK LOOK}

\section{Current knowledge}

Ventilator-associated pneumonia (VAP) is one of the most common hospital-acquired infections. Patients with VAP have longer durations of mechanical ventilation, longer ICU and hospital stay, and higher mortality than those without VAP. The Centers for Disease Control and Prevention has published a new algorithm for surveillance of ventilator-associated events. This algorithm focuses on identifying mechanically ventilated patients with worsening respiratory status, on the basis of changes in PEEP and $\mathrm{F}_{\mathrm{IO}_{2}}$, to aid in identifying infection-related ventilator-associated complications (IVACs).

\section{What this paper contributes to our knowledge}

In a group of subjects with high-risk trauma, the IVAC surveillance algorithm had a low sensitivity and a low positive predictive value for identification of VAP. The algorithm failed to diagnose nearly $75 \%$ of subjects with VAP. The IVAC algorithm also identified subjects requiring increasing ventilatory support due to a range of conditions unrelated to VAP. The use of ventilatorassociated event monitoring in this population requires further refinement.

\section{Methods}

\section{Setting and Patient Population}

This retrospective study was approved by the institutional review board at Massachusetts General Hospital, Boston, Massachusetts with a waiver of informed consent as a retrospective design of the study. Massachusetts General Hospital is a large university-affiliated, tertiary care referral and level-1 trauma center. Since 2005, data of all trauma patients admitted to our hospital have been prospectively collected in the Massachusetts General Hospital trauma registry database as a part of the National Trauma Data Bank. They include volume, acuity, age, stay, average ICU stay, ventilator days, and mortality. Patients in the Massachusetts General Hospital trauma registry database admitted to the hospital between July 1, 2009, and December 31, 2013, were eligible for inclusion in this study. They were included if they were at least $18 \mathrm{y}$ old, admitted to the ICU after trauma, required endotracheal intubation and mechanical ventilator support for at least $48 \mathrm{~h}$, and received a minimum of 1 unit of packed red blood cell transfusion during their mechanical ventilator support. Patients were excluded if they had tracheostomy placed upon arrival to ICU, were transferred from other hospitals after trauma, or died within $48 \mathrm{~h}$ after ICU admission. 


\section{Data Collection}

Prospectively collected data of each included subject were retrieved from both electronic and paper medical records. Demographic data, including age, sex, weight, height, race, $\mathrm{ABO}$ blood group, past medical history and Charlson comorbidity index $(\mathrm{CCI})^{21}$ were collected. Acuity of illness scores, including the Acute Physiology and Chronic Health Evaluation (APACHE) II score, ${ }^{22}$ the Sequential Organ Failure Assessment (SOFA) score, ${ }^{23}$ mechanism of injury, the injury severity score, ${ }^{24}$ and laboratory values were also recorded. Daily data, including vital signs, laboratory values, chest radiographs, modes of mechanical ventilator support, levels of PEEP, and $\mathrm{F}_{\mathrm{IO}_{2}}$, were recorded until patients were transferred to floor or died. At our institution, a chest radiograph was routinely taken every morning in all intubated patients. A sputum sample was collected for bacterial cultures when a new infiltrate was seen on the chest radiograph and/or fever associated with leukocytosis (white blood cell count $>10,000$ cells $/ \mathrm{mm}^{3}$ ) was observed. Surveillance cultures were not implemented as part of the routine care at our institute. Clinical outcomes, including duration of mechanical ventilator support, ventilator-free days at $28 \mathrm{~d}$, requirement of re-intubation and/or tracheostomy, length of ICU and hospital stay, hospital mortality, and causes of death were also collected. For subjects with IVAC, onset of the event, timing and appropriateness of initial antimicrobial therapy, and microbiologic results were additionally recorded. Appropriate therapy was defined as proper antibiotic coverage of all of the identified pathogens.

\section{Definition of IVAC}

The definition of IVAC in this study was based on the recent publication from the CDC. ${ }^{5}$ In brief, subjects would meet the criteria for the diagnosis of IVAC if they had a sustained increase of daily PEEP levels $\geq 3 \mathrm{~cm} \mathrm{H}_{2} \mathrm{O}$ or a sustained increase of daily $\mathrm{F}_{\mathrm{IO}_{2}} \geq 0.20$ for at least 2 consecutive days after 2 or more consecutive days of stable or decreasing daily minimum PEEP levels or $\mathrm{F}_{\mathrm{IO}_{2}}$ values plus had (1) temperature of $>38^{\circ} \mathrm{C}$ or $<36^{\circ} \mathrm{C}$ or white blood cell counts of $\geq 12,000$ cells $/ \mathrm{mm}^{3}$ or $\leq 4,000$ cells $/ \mathrm{mm}^{3}$ and (2) new antimicrobial agents started and continued for $\geq 4$ consecutive days. If IVAC subjects had pulmonary infection as evidenced by purulent respiratory secretions and/or positive culture of lower respiratory tract specimens, they were classified as possible VAP or probable VAP, respectively, according to the definition. ${ }^{5}$ To make a diagnosis of IVAC, first, ventilator-associated events were captured by using CDC-designed software ${ }^{5}$ and the dedicated database from the Respiratory Care Department, in which the lowest $\mathrm{F}_{\mathrm{IO}_{2}}$ and the lowest PEEP in every $12 \mathrm{~h}$ of all invasively ventilated patients were listed. This in- formation was then sent to the Infection Control Department, who continued the analysis of IVAC and possible and probable VAP. None of the individuals from the Respiratory Care Department or the Infection Control Department were involved in this paper.

\section{Definition of VAP}

Subjects were considered to have VAP if they met the criteria according to the CDC and NHSN definition published in $2008,{ }^{3}$ and we considered these criteria as the reference diagnosis in this study. The criteria consisted of (1) $\geq 2$ serial chest $x$-rays with new or progressive and persistent infiltration, consolidation, and/or cavitation; (2) signs/symptoms of fever $\left(>38^{\circ} \mathrm{C}\right)$ and/or leukopenia or leukocytosis (white blood cell counts of $<4,000$ or $\geq 12,000$ cells $/ \mathrm{mm}^{3}$, respectively) plus new onset of purulent sputum, change in character of sputum, or increased respiratory secretions; new onset or worsening cough, dyspnea, or tachypnea; rales or bronchial breath sounds; and/or worsening gas exchange; and (3) positive growth in blood culture, culture of pleural fluid, or culture from minimally contaminated lower respiratory tract specimens. The decision that VAP was present was determined by the infection control committee, which included a respiratory therapist, an infectious disease physician, and 2 infection control nurses. To make the diagnosis of VAP, the committee reviewed all of the subject's medical records, including daily chest x-rays interpreted by board-certificated radiologists. None of the infection control committee members were involved in this paper.

\section{Study End Points}

Our primary end point was the accuracy of the IVAC definition to identify VAP in subjects with high-risk trauma. We used the VAP-NHSN definition from the CDC/NHSN in $2008^{3}$ as the reference diagnosis of VAP. Our secondary end point was to describe outcomes and incidence of respiratory complications of subjects with IVAC alone, with VAP-NHSN alone, with both IVAC and VAP-NHSN, or without IVAC and VAP-NHSN.

\section{Statistical Analysis}

The IVAC definition was tested for sensitivity, specificity, and positive and negative predictive values for the diagnosis of VAP as defined by the 2008 CDC/NHSN definition $^{3}$ in subjects with high-risk trauma. Continuous variables were compared between groups using the MannWhitney U test. Categorical variables were compared between groups using the chi-square test or the Fisher exact test when appropriate. All comparisons were unpaired, all tests of significance were 2-tailed, and a $P$ value of $<.05$ 


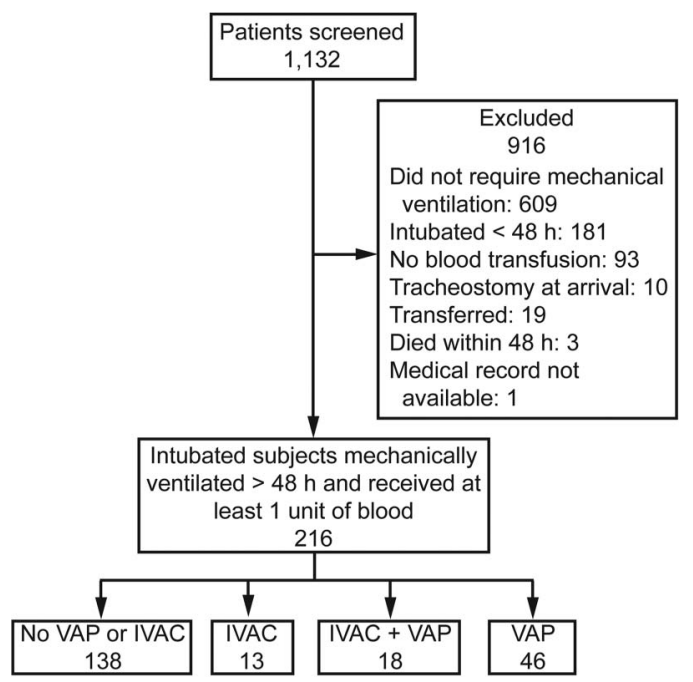

Fig. 1. Flow chart. VAP = ventilator-associated pneumonia; IVAC $=$ infection-related ventilator-associated complication.

was considered statistically significant. Statistical analyses were performed using SPSS 16.0 for Windows (SPSS, Chicago, Illinois).

\section{Results}

From the Massachusetts General Hospital trauma registry database between July 1, 2009, and December 31, 2013, there were 1,132 trauma patients screened for inclusion (Fig. 1). Of these, 916 patients did not meet the inclusion criteria (609 did not require mechanical ventilator support; 181 were intubated for $<48 \mathrm{~h} ; 93$ did not receive a packed red blood cell transfusion during mechanical ventilator support; 10 had tracheostomy placed upon ICU arrival; 19 were transferred from other hospitals after trauma; 3 died within $48 \mathrm{~h}$ after ICU admission; and from 1 patient, the medical record could not be retrieved), leaving 216 subjects for analysis. Overall, there were 77 (35.6\%) subjects who met the definition of IVAC and/or VAPNHSN. Of these, 31 (14.4\%) subjects were identified as IVAC, $64(29.6 \%)$ as VAP-NHSN, and $18(8.3 \%)$ as both IVAC and VAP-NHSN (Fig. 1). These corresponded to incidences of IVAC and VAP-NHSN of 16.6 and 34.2 events per 1,000 ventilator days, respectively. The sensitivity, specificity, and positive and negative predictive values of IVAC for VAP-NHSN diagnosis were $28.1 \%$ (95\% CI, $17.6-40.8 \%$ ), 91.5\% (95\% CI, $85.8-95.4 \%$ ), $58.1 \%$ (95\% CI, $17.6-75.4 \%$ ), and $75.1 \%$ (95\% CI, 68.3$81.2 \%$ ), respectively (Table 1 ).

Table 2 shows the demographic data of all subjects. There was no significant difference in the demographic data between subjects with VAP-NHSN only, with IVAC only, with both VAP-NHSN and IVAC, and without VAPNHSN and IVAC except that subjects with both IVAC and
Table 1. Test Characteristics of Infection-Related VentilatorAssociated Complications for the Diagnosis of VentilatorAssociated Pneumonia

\begin{tabular}{|c|c|c|c|}
\hline & VAP & No VAP & Total \\
\hline IVAC & 18 & 13 & $31 *$ \\
\hline No IVAC & 46 & 139 & $185 \dagger$ \\
\hline Total & $64 \div$ & $152 \S$ & 216 \\
\hline \multicolumn{4}{|c|}{$\begin{array}{l}\text { * Positive predictive value } 58.1 \% \text { (95\% CI, } 17.6-75.4 \%) \text {. } \\
\dagger \text { Negative predictive value } 75.1 \%(95 \% \mathrm{CI}, 68.3-81.2 \%) \text {. } \\
\text { ‡ Sensitivity } 28.1 \%(95 \% \mathrm{CI}, 17.6-40.8 \%) . \\
\text { § Specificity } 91.5 \%(95 \% \mathrm{CI}, 85.8-95.4 \%) . \\
\text { VAP = ventilator-associated pneumonia } \\
\text { IVAC = infection-related ventilator-associated complications }\end{array}$} \\
\hline
\end{tabular}

VAP-NHSN had higher injury severity scores than those with VAP-NHSN only and those without VAP-NHSN and IVAC (median 38 [interquartile range 27-58] vs 34 [2938 ], $P=.044$ and 38 [27-58] vs 29 [22-38], $P=.007$, respectively).

In the cohort of 21 subjects with IVAC (Table 3), IVAC subjects with VAP-NHSN had antibiotics initiated later than IVAC subjects without VAP-NHSN $(1.7 \pm 3.6 \mathrm{~d}$ vs $-0.8 \pm 1.3 \mathrm{~d}, P=.01)$. There was no difference in appropriateness and duration of antibiotic administration as well as microbiology results between groups.

Table 4 shows the clinical outcomes of all subjects. Overall, subjects with IVAC and/or VAP-NHSN had higher morbidity when compared with those without IVAC and VAP-NHSN. Subjects with IVAC only had a lower tracheostomy rate compared with those with VAP-NHSN only $(23.1 \%$ vs $67.4 \%, P=.004)$ and those with both IVAC and VAP-NHSN (23.1\% vs $61.1 \%, P=.036)$. They also had shorter mechanical ventilator duration compared with those with both IVAC and VAP-NHSN (median 207 [interquartile range 124-295] h vs 258 [214-422] h, $P=.045)$ and shorter hospital length of stay compared with those with VAP-NHSN (21 [13-25] d vs 25 [20$39] \mathrm{d}, P=.033)$. There was no significant difference in clinical outcomes between subjects with VAP-NHSN only and those with both IVAC and VAP-NHSN.

\section{Discussion}

The main finding of our study is that, in subjects with high-risk trauma, the IVAC criteria had poor sensitivity and poor positive predictive value for the diagnosis of VAP according to the $2008 \mathrm{CDC} / \mathrm{NHSN}$ definition. ${ }^{3}$ Our study confirmed the low sensitivity of IVAC to detect VAP-NHSN, with a value comparable with what has been already reported in large heterogenic critically ill populations. ${ }^{6,8,10}$ Incidences of IVAC and VAP-NHSN in our 
Table 2. Demographic Data of All Subjects

\begin{tabular}{|c|c|c|c|c|}
\hline & VAP Only $(n=46)$ & IVAC Only $(n=13)$ & $\begin{array}{l}\text { Both IVAC and VAP } \\
\qquad(n=18)\end{array}$ & $\begin{array}{c}\text { No IVAC or VAP } \\
\quad(n=139)\end{array}$ \\
\hline Age, median (IQR) y & $50.7(27.0-66.4)$ & $37.2(25.4-62.0)$ & $50.0(33.3-62.7)$ & $45.4(28.9,61.8)$ \\
\hline Male sex, $n(\%)$ & $36(78.3)$ & $11(84.6)$ & $17(94.4 \%)^{*}$ & $94(67.6 \%)$ \\
\hline Weight, median (IQR) $\mathrm{kg}$ & 77 (70-87) & $86(82-100)$ & $82(77-92)$ & $77(66-87)$ \\
\hline Height, median (IQR) $\mathrm{cm}$ & $173(168-180)$ & $175(168-183)$ & $177(171-183)$ & $173(165-178)$ \\
\hline ABO type $\mathrm{O}, n(\%)$ & $21(45.7)$ & $8(61.5)$ & $13(72.2)$ & $75(54.0)$ \\
\hline Caucasian, $n(\%)$ & $25(54.3)$ & $9(69.2)$ & $10(55.6)$ & $82(59.0)$ \\
\hline \multicolumn{5}{|l|}{ Past medical history, $n(\%)$} \\
\hline Cardiovascular & $7(15.2)$ & $1(7.7)$ & $2(11.1)$ & $8(5.8)$ \\
\hline Pulmonary & $4(8.7)$ & $3(23.1)$ & $0(0.0)$ & $12(8.6)$ \\
\hline Neurological & $3(6.5)$ & $1(7.7)$ & $0(0.0)$ & $2(1.4)$ \\
\hline Renal & $1(2.2)$ & $1(7.7)$ & $0(0.0)$ & $3(2.2)$ \\
\hline Diabetes mellitus & $5(10.9)$ & $1(7.7)$ & $3(16.7)$ & $11(7.9)$ \\
\hline CCI, median (IQR) score & $0(0-1)$ & $0(0-1)$ & $0(0-1)$ & $0(0-1)$ \\
\hline APACHE II, median (IQR) score & $17(13-21)$ & $14(12-25)$ & $14(10-21)$ & $15(11-19)$ \\
\hline SOFA, median (IQR) score & $8(5-10)$ & $7(4-9)$ & $6(5-9)$ & $7(4-8)$ \\
\hline Blunt mechanism, $n(\%)$ & $42(91.3)$ & $11(84.6)$ & $18(100.0)$ & $125(89.9)$ \\
\hline ISS, median (IQR) & $34(29-38) \dagger$ & $34(29-41)$ & $38(27-58)^{*}$ & $29(22-38)$ \\
\hline AIS head, median (IQR) score & $1(0-3)$ & $2(2-4)$ & $3(0-5)$ & $1(0-3)$ \\
\hline AIS chest, median (IQR) score & $3(3-4)$ & $3(3-4)$ & $4(0-4)$ & $3(0-4)$ \\
\hline WBC, median (IQR) thousand $/ \mathrm{mm}^{3}$ & $11.8(8.9-18.2)$ & $15.4(13.0-19.5)$ & $14.3(9.4-16.4)$ & $13.9(10.0-18.3)$ \\
\hline Hemoglobin, median (IQR) g/dL & $10.4(8.8-12.0) \ddagger$ & $9.1(8.1-9.8)$ & $9.5(7.8-12.6)$ & $10.5(8.7-12.4)$ \\
\hline Platelet, median (IQR) thousand $/ \mathrm{mm}^{3}$ & $162(135-224)$ & $227(114-326)$ & $172(69-209)$ & $167(121-221)$ \\
\hline PRBC, median (IQR) units & $2(1-8)$ & $5(3-13)$ & $3(2-6)$ & $3(2-8)$ \\
\hline $\begin{array}{l}\text { *P } P<0.05 \text {, compared with group with no infectio } \\
\dagger P<0.05 \text {, compared with group with both infect } \\
\ddagger P<0.05 \text {, compared with group with infection-re } \\
\text { VAP = ventilator-associated pneumonia } \\
\text { IVAC = infection-related ventilator-associated com } \\
\text { CCI = Charlson comorbidity index } \\
\text { APACHE = Acute Physiology and Chronic Health } \\
\text { SOFA = Sequential Organ Failure Assessment } \\
\text { ISS = injury severity score } \\
\text { AIS = abbreviated injury scale } \\
\text { PRBC = packed red blood cells }\end{array}$ & $\begin{array}{l}\text { d ventilator-associated complic } \\
\text { ted ventilator-associated comp } \\
\text { entilator-associated complicati } \\
\text { ns } \\
\text { tion }\end{array}$ & $\begin{array}{l}\text { or ventilator-associated pneun } \\
\text { ns and ventilator-associated pn } \\
\text { ly. }\end{array}$ & & \\
\hline
\end{tabular}

homogeneous high-risk trauma patient population were 16.6 and 34.2 events per 1,000 ventilator days, respectively. These were higher than those reported in heterogeneous mechanically ventilated subjects (IVAC, 3.6-8.8 and VAP, 3.0-10.0 events/1,000 ventilator days).6,8,10,12 The deviation of our finding from other reports can be justified by the difference in patient population. Our study focused on critically ill subjects with trauma with a high risk of respiratory compromise as well as VAP.

In our study, there were $13(41.9 \%)$ of 31 IVAC subjects who did not meet the 2008 CDC/NHSN criteria for VAP diagnosis ${ }^{3}$ (Table 1 and Fig. 1). This was mainly due to the absence of any change in chest radiographs consistent with the diagnosis of VAP-NHSN. The possible causes of worsening oxygenation and subsequent manipulation of mechanical ventilator support in these 13 subjects were pulmonary edema in 6 cases, atelectasis in 5 cases, pulmonary contusion in 1 case, and underlying pulmonary fibrosis in 1 case. Our findings were supported by the fact that the ventilator-associated event surveillance potentially identifies mechanically ventilated patients who have worsening respiratory status due not only to VAP but possibly to different pulmonary complications, such as ARDS, atelectasis, pulmonary embolism, and pulmonary edema as well as extrapulmonary causes, such as abdominal compartmental syndrome or sepsis. ${ }^{6-11}$

On the other hand, there were $46(71.9 \%)$ of 64 subjects with VAP diagnosed according to the 2008 CDC/NHSN definition $^{3}$ that had no IVAC identified (Table 1 and Fig. 1). Of these, 38 did not meet the criterion of increase in daily minimum PEEP levels or $\mathrm{F}_{\mathrm{IO}_{2}}$ values for $\geq 2$ consecutive days, and 8 did not have a previous stable period of PEEP levels or $\mathrm{F}_{\mathrm{IO}_{2}}$ values for $\geq 2$ consecutive days. Our finding was consistent with recent literature. ${ }^{8,10}$ It is noteworthy that the IVAC criteria did not detect almost three quarters of subjects with VAP-NHSN, although this group of subjects showed higher morbidities and worse clinical outcomes than the other groups. This should be 


\section{IVAC for VAP Surveillance in Trauma Subjects}

Table 3. Antibiotics and Microbiology Results in Subjects With Infection-Related Ventilator-Associated Complications With Versus Without Ventilator-Associated Pneumonia

\begin{tabular}{|c|c|c|c|}
\hline & \multicolumn{2}{|c|}{ Subjects With IVAC } & \multirow{2}{*}{$P$} \\
\hline & $\operatorname{VAP}(n=18)$ & No VAP $(n=13)$ & \\
\hline \multicolumn{4}{|c|}{ Time from IVAC to antibiotics, $\mathrm{d}$} \\
\hline Mean \pm SD & $1.7 \pm 3.6$ & $-0.8 \pm 1.3$ & .01 \\
\hline Median (IQR) & $0.5(-0.3$ to 3.0$)$ & $-1.0(-2.0$ to 0.0$)$ & .006 \\
\hline Appropriateness, $n(\%)$ & $18(100.0)$ & $11(84.6)$ & .19 \\
\hline \multicolumn{4}{|l|}{ Initial antibiotics, $n(\%)$} \\
\hline Vancomycin & $13(72.2)$ & $12(92.3)$ & .36 \\
\hline Cefepime & $9(50.0)$ & $12(92.3)$ & .02 \\
\hline Metronidazole & $0(0.0)$ & $3(23.1)$ & .06 \\
\hline Tobramycin & $2(11.1)$ & $0(0.0)$ & .50 \\
\hline Piperacillin/Tazobactam & $2(11.1)$ & $0(0.0)$ & .50 \\
\hline \multicolumn{4}{|l|}{ Duration of antibiotics, $\mathrm{d}$} \\
\hline Mean \pm SD & $8.7 \pm 3.4$ & $10.2 \pm 6.7$ & .44 \\
\hline Median (IQR) & $9(6-11.5)$ & $10(5-13)$ & .75 \\
\hline \multicolumn{4}{|l|}{ Microbiology results, $n(\%)$} \\
\hline 1 organism isolated & $12(66.7)$ & $9(69.2)$ & $>.99$ \\
\hline$>1$ organism isolated & $6(33.3)$ & $2(15.4)$ & .41 \\
\hline MSSA & $3(16.7)$ & $2(15.4)$ & $>.99$ \\
\hline MRSA & $1(5.6)$ & $1(7.7)$ & $>.99$ \\
\hline Enterobacter spp. & $4(22.2)$ & $0(0.0)$ & .12 \\
\hline Klebsiella spp. & $2(11.1)$ & $2(15.4)$ & $>.99$ \\
\hline Escherichia coli & $3(16.7)$ & $0(0.0)$ & .25 \\
\hline Stenotrophomonas spp. & $2(11.1)$ & $1(7.7)$ & $>.99$ \\
\hline Haemophilus influenzae & $2(11.1)$ & $0(0.0)$ & .50 \\
\hline Pseudomonas aeruginosa & $2(11.1)$ & $0(0.0)$ & .50 \\
\hline Other GNR & $2(11.1)$ & $3(23.1)$ & .63 \\
\hline Others & $3(16.7)$ & $4(30.8)$ & .41 \\
\hline $\begin{array}{l}\text { IVAC }=\text { infection-related ventilator-a } \\
\text { VAP = ventilator-associated pneumor } \\
\text { IQR = interquartile range } \\
\text { MSSA = methicillin-sensitive Staphy } \\
\text { MRSA = methicillin-resistant Staphy } \\
\text { GNR = Gram-negative rod }\end{array}$ & & & \\
\hline
\end{tabular}

Table 4. Clinical Outcomes of All Subjects

\begin{tabular}{|c|c|c|c|c|}
\hline & VAP Only $(n=46)$ & IVAC Only $(n=13)$ & $\begin{array}{l}\text { Both IVAC and VAP } \\
\quad(n=18)\end{array}$ & $\begin{array}{c}\text { No IVAC or VAP } \\
(n=139)\end{array}$ \\
\hline Re-intubation, $n(\%)$ & $7(15.2)$ & $5(38.5)^{*}$ & $2(11.1)$ & $18(12.9)$ \\
\hline Tracheostomy, $n(\%)$ & $31(67.4)^{*} *$ & $3(23.1) \dagger$ & $11(61.1)^{*}$ & $49(35.3)$ \\
\hline Mechanical ventilation duration, median (IQR) h & $263(219-395)^{*}$ & $207(124-295)^{* \dagger}$ & $258(214-422)^{*}$ & $139(80-229)$ \\
\hline Mechanical ventilator-free days, median (IQR) d & $15(10-19)^{*}$ & $16(13-23)$ & $10(0-18)^{*}$ & $20(9-24)$ \\
\hline ICU LOS, median (IQR) d & $16(10-20)^{*}$ & $12(5-16)$ & $14(10-21)^{*}$ & $8(6-13)$ \\
\hline Hospital LOS, median (IQR) d & $25(20-39)^{*}+$ & $21(13-25)$ & $28(17-40)$ & $19(11-31)$ \\
\hline Hospital mortality, $n(\%)$ & $8(17.4)$ & $4(30.8)$ & $7(38.9)$ & $31(22.3)$ \\
\hline 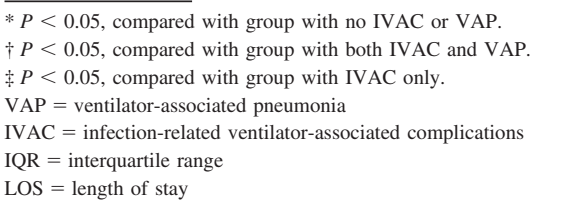 & & & & \\
\hline
\end{tabular}




\section{IVAC for VAP Surveillance in Trauma Subjects}

considered as an important limitation of the usefulness of the IVAC definition in identifying patients with VAPNHSN.

In addition, our study showed that subjects with IVAC who also had VAP-NHSN had antibiotics initiated later than those who had IVAC only, for which we do not have an explanation. Those subjects also required longer duration of mechanical ventilator support as well as more often requiring tracheostomy for ventilatory management and weaning. It has been clearly demonstrated that early appropriate therapy improves outcome in critically ill patients and that delayed initiation of appropriate antibiotics for VAP has been associated with increased mortality. ${ }^{25,26}$ However, it has also been suggested that it would be advisable to initiate targeted antimicrobial therapy after microbiological evidence and identification of infection. ${ }^{27}$ Interestingly, a recent study, regarding the timing of antibiotic administration after identification of a ventilatorassociated event, demonstrated that there was no association between timing of antibiotics and mortality, superinfection, or treatment failure in critically ill subjects. ${ }^{28}$ Nevertheless, we could not conclude from our study whether delay in the initiation of antibiotics resulted in these adverse events or was only a mere statistical association. In addition, the surveillance culture protocol has not been implemented as routine care at our institution. The results of surveillance cultures might influence the appropriateness of antibiotic choice.

Our study had some limitations. First, as a singlecenter study focusing on homogeneous very critically ill subjects with trauma as well as a very high risk of VAP, our study results might not be applicable to other critical care settings. Second, VAP in our study was defined according to the $2008 \mathrm{CDC} / \mathrm{NHSN}$ definition, ${ }^{3}$ which is generally considered as an accepted diagnosis of VAP. Currently, a standard diagnosis of VAP does not exist. However, almost all of the existing data on VAP prevention are based on this traditional definition. ${ }^{12}$ Third, as a retrospective study, some risk factors that might potentiate the development of ventilator-associated events, such as overly positive fluid balance, mode of mechanical ventilation, or medication administered, ${ }^{7}$ were not considered in our analysis. However, these factors would not be expected to significantly change the accuracy of the IVAC definition in identifying patients with VAP, which was our primary end point. Fourth, we chose to test the accuracy of the IVAC definition in identifying VAP according to the 2008 CDC/NHSN definition in our study despite the fact that the IVAC definition is likely to identify patients who have either pulmonary or extrapulmonary causes that result in severe deterioration of respiratory function. ${ }^{5}$ Finally, our sample size might be insufficient to detect significant differences in major clinical outcomes, such as mortality.

\section{Conclusions}

Our study demonstrated that the IVAC surveillance algorithm has a low sensitivity and a low positive predictive value for the identification of VAP in subjects with highrisk trauma. The algorithm failed to diagnose about three quarters of subjects with VAP-NHSN. Additionally, the IVAC algorithm identified subjects requiring increasing ventilator support due to a range of conditions unrelated to VAP. Further investigations are required to determine the usefulness of the ventilator-associated event surveillance algorithm in detecting respiratory infections in mechanically ventilated patients.

\section{REFERENCES}

1. Rello J, Ollendorf DA, Oster G, Vera-Llonch M, Bellm L, Redman $\mathrm{R}$, et al. Epidemiology and outcomes of ventilator-associated pneumonia in a large US database. Chest 2002;122(6):2115-2121.

2. Melsen WG, Rovers MM, Groenwold RH, Bergmans DC, Camus C, Bauer TT, et al. Attributable mortality of ventilator-associated pneumonia: a meta-analysis of individual patient data from randomised prevention studies. Lancet Infect Dis 2013;13(8):665-671.

3. Horan TC, Andrus M, Dudeck MA. CDC/NHSN surveillance definition of health care-associated infection and criteria for specific types of infections in the acute care setting. Am J Infect Control 2008;36(5):309-332.

4. Klompas M. Interobserver variability in ventilator-associated pneumonia surveillance. Am J Infect Control 2010;38(3):237-239.

5. Magill SS, Klompas M, Balk R, Burns SM, Deutschman CS, Diekema $\mathrm{D}$, et al. Developing a new, national approach to surveillance for ventilator-associated events. Crit Care Med 2013;41(11):2467-2475.

6. Boyer AF, Schoenberg N, Babcock H, McMullen KM, Micek ST, Kollef MH. A prospective evaluation of ventilator-associated conditions and infection-related ventilator-associated conditions. Chest 2015;147(1):68-81.

7. Hayashi Y, Morisawa K, Klompas M, Jones M, Bandeshe H, Boots $\mathrm{R}$, et al. Toward improved surveillance: the impact of ventilatorassociated complications on length of stay and antibiotic use in patients in intensive care units. Clin Infect Dis 2013;56(4):471-477.

8. Klein Klouwenberg PM, van Mourik MS, Ong DS, Horn J, Schultz MJ, Cremer OL, et al. Electronic implementation of a novel surveillance paradigm for ventilator-associated events. Feasibility and validation. Am J Respir Crit Care Med 2014;189(8):947-955.

9. Klompas M, Khan Y, Kleinman K, Evans RS, Lloyd JF, Stevenson $\mathrm{K}$, et al. Multicenter evaluation of a novel surveillance paradigm for complications of mechanical ventilation. PLoS One 2011;6(3): e18062.

10. Lilly CM, Landry KE, Sood RN, Dunnington CH, Ellison RT, 3rd, Bagley $\mathrm{PH}$, et al. Prevalence and test characteristics of national health safety network ventilator-associated events. Crit Care Med 2014;42(9):2019-2028.

11. Muscedere J, Sinuff T, Heyland DK, Dodek PM, Keenan SP, Wood $\mathrm{G}$, et al. The clinical impact and preventability of ventilator-associated conditions in critically ill patients who are mechanically ventilated. Chest 2013;144(5):1453-1460. 


\section{IVAC for VAP Surveillance in Trauma Subjects}

12. Lewis SC, Li L, Murphy MV, Klompas M, CDC Prevention Epicenters. Risk factors for ventilator-associated events: a case-control multivariable analysis. Crit Care Med 2014;42(8):1839-1848.

13. Magill SS, Rhodes B, Klompas M. Improving ventilator-associated event surveillance in the National Healthcare Safety Network and addressing knowledge gaps: update and review. Curr Opin Infect Dis 2014;27(4):394-400.

14. Cook A, Norwood S, Berne J. Ventilator-associated pneumonia is more common and of less consequence in trauma patients compared with other critically ill patients. J Trauma 2010;69(5):1083-1091.

15. Michetti CP, Fakhry SM, Ferguson PL, Cook A, Moore FO, Gross R, AAST Ventilator-Associated Pneumonia Investigators. Ventilator-associated pneumonia rates at major trauma centers compared with a national benchmark: a multi-institutional study of the AAST. J Trauma Acute Care Surg 2012;72(5):1165-1173.

16. Antonelli M, Moro ML, Capelli O, De Blasi RA, D’Errico RR, Conti $\mathrm{G}$, et al. Risk factors for early onset pneumonia in trauma patients. Chest 1994;105(1):224-228.

17. Cavalcanti M, Ferrer M, Ferrer R, Morforte R, Garnacho A, Torres A. Risk and prognostic factors of ventilator-associated pneumonia in trauma patients. Crit Care Med 2006;34(4):1067-1072.

18. Croce MA, Tolley EA, Claridge JA, Fabian TC. Transfusions result in pulmonary morbidity and death after a moderate degree of injury. J Trauma 2005;59(1):19-23; discussion 23-24.

19. Weinberg JA, McGwin G Jr, Marques MB, Cherry SA 3rd, Reiff DA, Kerby JD, Rue LW 3rd. Transfusions in the less severely injured: does age of transfused blood affect outcomes? J Trauma 2008; 65(4):794-798.

20. Vandromme MJ, McGwin G Jr, Marques MB, Kerby JD, Rue LW 3rd, Weinberg JA. Transfusion and pneumonia in the trauma intensive care unit: an examination of the temporal relationship. J Trauma 2009;67(1):97-101
21. Charlson ME, Pompei P, Ales KL, MacKenzie CR. A new method of classifying prognostic comorbidity in longitudinal studies: development and validation. J Chronic Dis 1987;40(5):373-383

22. Knaus WA, Draper EA, Wagner DP, Zimmerman JE. APACHE II: a severity of disease classification system. Crit Care Med 1985; 13(10):818-829.

23. Vincent JL, Moreno R, Takala J, Willatts S, De Mendonça A, Bruining $\mathrm{H}$, et al. The SOFA (sepsis-related organ failure assessment) score to describe organ dysfunction/failure: on behalf of the Working Group on Sepsis-Related Problems of the European Society of Intensive Care Medicine. Intensive Care Med 1996;22(7): 707-710.

24. Osler T, Baker SP, Long W. A modification of the injury severity score that both improves accuracy and simplifies scoring. J Trauma 43(6):922-925, 1997; discussion 925-926.

25. Clec'h C, Timsit JF, De Lassence A, Azoulay E, Alberti C, Garrouste-Orgeas $\mathrm{M}$, et al. Efficacy of adequate early antibiotic therapy in ventilator-associated pneumonia: influence of disease severity. Intensive Care Med 2004;30(7):1327-1333.

26. Luna CM, Aruj P, Niederman MS, Garzón J, Violi D, Prignoni A, et al. Appropriateness and delay to initiate therapy in ventilatorassociated pneumonia. Eur Respir J 2006;27(1):158-164.

27. Hranjec T, Rosenberger LH, Swenson B, Metzger R, Flohr TR, Politano AD, et al. Aggressive versus conservative initiation of antimicrobial treatment in critically ill surgical patients with suspected intensive-care-unit-acquired infection: a quasi-experimental, before and after observational cohort study. Lancet Infect Dis 2012;12(10): 774-780.

28. Amaral AC, Holder MW. Timing of antimicrobial therapy after identification of ventilator-associated condition is not associated with mortality in patients with ventilator-associated pneumonia: a cohort study. PLoS One 2014;9(5):e97575.

This article is approved for Continuing Respiratory Care Education credit. For information and to obtain your CRCE

(free to AARC members) visit

www.rcjournal.com

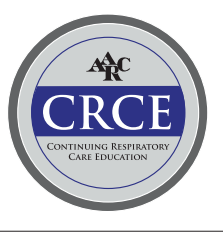

